\title{
Immunological Instability of Persistent Adenovirus Vectors in the Brain: Peripheral Exposure to Vector Leads to Renewed Inflammation, Reduced Gene Expression, and Demyelination
}

\author{
Andrew P. Byrnes, Robert E. MacLaren, and Harry M. Charlton \\ Department of Human Anatomy, University of Oxford, Oxford OX13QX, United Kingdom
}

\begin{abstract}
Nonreplicating adenovirus vectors are being developed as vehicles for the delivery of therapeutic genes in vivo. Whereas in many organs an antiviral $\mathrm{T}$ cell response eliminates the vector and damages local tissue, when adenovirus vectors are injected into the brain the subsequent immune attack can be ineffective, allowing the vector to persist.

In the present study, E1-deleted human adenovirus vectors were injected into the caudate nucleus of rats. Two months later, expression of protein from the vector was still evident and little inflammation was seen. A subcutaneous injection of adenovirus vector at this time, however, led within 2 weeks to severe mononuclear inflammation and microglial activation in the caudate. This caused local demyelination and a decrease in detectable protein expression from the vector. Interestingly, intense microglial activation and numerous lymphocytes and
\end{abstract}

monocytes were also seen in brain areas containing neurons capable of retrogradely transporting the adenovirus vector from the caudate. Control experiments established that this inflammation in distant brain areas was not a nonspecific consequence of degeneration.

These experiments demonstrate that although adenovirus vectors can persist in the brain without causing chronic inflammation, they remain the potential target of a damaging cellmediated immune response brought about by a subsequent peripheral exposure to vector. The finding of lymphocytes in brain areas that project to the caudate further shows that viral antigens that are retrogradely transported by neurons can also be the target of a T cell attack.

Key words: adenovirus; neuroimmunology; gene therapy; viral vector; demyelination; microglia; caudate
The immune system forms one of the biggest barriers to using nonreplicating viruses as therapeutic and experimental tools in vivo. Although viral vectors are very efficient at delivering DNA into animal and human tissues, they cause inflammation and provoke $T$ lymphocyte responses that can destroy vectortransduced cells and lead to tissue damage. Studies of the inflammatory response to such vectors in the brain are providing insight into the unusual immunology of this organ.

The immune response to human adenovirus type 5 vectors has lately been the subject of intensive investigation. These vectors are replication-incompetent: in addition to a species-specific block that prevents the virus from productively replicating in rat or mouse cells, deletion of the adenovirus E1 region greatly decreases expression of viral proteins and effectively blocks viral DNA replication (Jones and Shenk, 1979; Ginsberg et al., 1991). Nevertheless, in organs such as the liver and lung a $T$ cell response to viral proteins eliminates adenovirus vector-transduced cells within a matter of weeks, causing pathology in the process (Yang et al., 1994, 1995). Long-term vector persistence generally requires immunosuppression or the use of very young animals with immature immune systems (Kass-Eisler et al., 1994).

By contrast, a number of studies have reported that adenovirus vector expression can last for extended periods of time in the brains of normal

\footnotetext{
Received Dec. 14, 1995; revised Feb. 6, 1996; accepted Feb. 13, 1996.

This work was supported by the Wellcome Trust and the Medical Research Council (UK). A.P.B. was the recipient of a Wellcome Prize Studentship and a Graduate Scholarship from Keble College (Oxford, UK). We thank Drs. M. J. A. Wood and V. H. Perry for helpful discussions, and Dr. M. McMenamin for preparing the HSV.

Correspondence should be addressed to Andrew P. Byrnes, Department of $\mathrm{Hu}-$ man Anatomy, University of Oxford, South Parks Road, Oxford OX1 3QX, UK. Copyright $\odot 1996$ Society for Neuroscience $0270-6474 / 96 / 163045-11 \$ 05.00 / 0$
}

adult rodents (Akli et al., 1993; Davidson et al., 1993; Le Gal La Salle et al., 1993; Byrnes et al., 1995). This occurs even though injection of adenovirus vector into the brain can cause upregulation of major histocompatibility complex (MHC) proteins and recruitment of leukocytes (Byrnes et al., 1995). However, inflammation in the brain is greatly diminished by 1 month after injection and is barely evident at 2 months, despite the continued presence of the vector.

In addition to transfecting cells at the site of injection in the brain, viral vectors are also retrogradely transported by neurons with axon terminals in the vicinity (Akli et al., 1993; Ridoux et al., 1994; Wood et al., 1994a). We have found that retrograde transport of adenovirus and herpes simplex virus vectors also leads to subsequent local inflammation in areas containing these neurons (Wood et al., 1994b; Byrnes et al., 1995). It was unclear in these studies whether this inflammation in afferent sites was mediated by $\mathrm{T}$ cells or some other, less specific process.

It is known that foreign antigens can survive in the brain for extended periods without inducing a cell-mediated immune response, yet the persisting antigens remain susceptible to attack after peripheral activation of antigen-specific T cells (Backes et al., 1990; Matyszak and Perry, 1995). To learn more about the ability of adenovirus vectors to survive in the brain, we tested whether persisting vector would be the larget of such an immune response after peripheral exposure to vector. Because it is unclear whether foreign antigens inside neurons can be effectively presented to $T$ cells, we were particularly interested in any inflammation at sites of retrograde vector uptake.

\section{MATERIALS AND METHODS}

Viruses. AdRL, an E1-deleted human adenovirus type 5 vector that contains the lac $Z$ gene (encoding $\beta$-galactosidase) under control of the 
Table 1. Experimental plan

\begin{tabular}{llllllll} 
& $\begin{array}{l}\text { Caudate } \\
\text { injection } \\
\text { on day }-60\end{array}$ & $\begin{array}{l}\text { Footpad } \\
\text { injection } \\
\text { on day 0 }\end{array}$ & & \multicolumn{3}{c}{$\begin{array}{l}\text { Number of rats } \\
\text { killed on day: }\end{array}$} \\
\cline { 4 - 8 } Experimental & AdRL & AdRL & 0 & 14 & 21 & 28 \\
\hline \multirow{3}{*}{ Controls } & AdRL & none & - & 3 & 4 & 4 \\
& AdRL & buffer & 2 & - & - & - \\
& AdRL & HSV-1 1803 & - & 2 & - & - \\
& AdRL & HSV-1 1803-lacZ & - & 2 & - & - \\
& UV-AdRL & AdRL & - & 2 & 1 & 1
\end{tabular}

Rats were injected in the right caudate with AdRL or UV-irradiated AdRL. After a delay of $60 \mathrm{~d}$, two animals were killed and the rest were injected in the footpad with AdRL, nonreplicating HSV-1 (with or without lacZ), or buffer. The number of animals killed on various days after the footpad injection is shown.

Rous sarcoma virus (RSV) LTR promoter, was prepared as described previously (Byrnes et al., 1995). It contains the dl309 E3 region. Virus was purified twice by $\mathrm{CsCl}$ density ultracentrifugation, and the buffer was exchanged on a Sephadex PD-10 column (Pharmacia, St. Albans, UK) with $10 \mathrm{mM}$ Tris, $\mathrm{pH} 7.5$, and $1 \mathrm{mM} \mathrm{MgCl}$. After passing through a sterile $0.2 \mu \mathrm{m}$ filter, virus was aliquoted and frozen until use. The titer, as determined by plaque assay on 293 cells, was $2 \times 10^{9}$ plaque-forming units $(\mathrm{pfu}) / \mathrm{ml}$. In some experiments, the vector was UV-irradiated to inactivate gene transcription, as described previously (Byrnes et al., 1995). Such virus was unable to replicate on 293 cells and did not express $\beta$-galactosidase in vitro or in vivo.

Herpes simplex virus type 1 (HSV-1) strain 1803 (Rixon and McLauchlan, 1990), a virus containing the temperature-sensitive mutation $t s K$ in ICP4, was a gift from Dr. F. J. Rixon (MRC Virology Unit, Glasgow, UK). A second virus, 1803-lacZ, was constructed by cloning an expression cassette containing the RSV promoter and $l a c Z$ into the $X b a \mathrm{I}$ site of 1803, according to the method of Rixon and McLauchlan (1990). The resulting virus expressed $\beta$-galactosidase both in vitro and in vivo. Both viruses were grown and titered on Vero cells at the permissive temperature of $32^{\circ} \mathrm{C}$ and used at a concentration of $2 \times 10^{7} \mathrm{pfu} / \mathrm{ml}$ in 150 $\mathrm{mm} \mathrm{NaCl}, 20 \mathrm{~mm}$ Tris, $\mathrm{pH} 7.5$.

Animals and surgical procedures. Adult Albino Oxford (AO) rats from the Department of Human Anatomy animal facility (conventionally housed and fed) were anesthetized with intraperitoneal hypnorm $(0.2$ $\mathrm{mg} / \mathrm{kg}$ fentanyl citrate and $6 \mathrm{mg} / \mathrm{kg}$ fluanisone, Janssen, Oxford, UK) and hypnovel ( $2 \mathrm{mg} / \mathrm{kg}$ midazolam, Roche, Welwyn, UK). Animals were placed in a stereotaxic injection apparatus (incisor bar set $2 \mathrm{~mm}$ below the interaural line) and injected twice in the right caudate (bregma, $3.5 \mathrm{~mm}$ lateral, $4.5 \mathrm{~mm}$ vertical from the dura, and $1 \mathrm{~mm}$ rostral, $3.5 \mathrm{~mm}$ lateral, $4.5 \mathrm{~mm}$ vertical $)$ with $0.5 \mu \mathrm{l}\left(1 \times 10^{6} \mathrm{pfu}\right)$ of $\mathrm{AdRL}$ per injection. An equivalent amount of UV-irradiated $\Lambda \mathrm{dRL}$ was used in some experiments. Each injection was made using a drawn glass micropipette over a period of $2 \mathrm{~min}$, with the pipette left in place for another 3-5 min before withdrawal. Three AdRL-injected rats were killed after 3 d for localization of $\beta$-galactosidase-positive cells by immunocytochemistry.

Sixty days after being injected in the caudate with AdRL, rats were anesthetized with ether and 11 were injected subcutaneously in the left hind footpad with $25 \mu$ l of AdRL $\left(5 \times 10^{7} \mathrm{pfu}\right)$, as shown in Table 1 . As controls for antigen specificity, another six rats were injected subcutane-

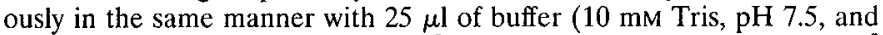
$1 \mathrm{mM} \mathrm{MgCl})$, HSV-1 $1803\left(5 \times 10^{5}\right.$ pfu $)$, or HSV-1 1803-lacZ $\left(5 \times 10^{5}\right.$ pfu). The dose of HSV-1 $t s K$ had been determined previously to cause a substantial and long-lasting immune response (Wood et al., 1994b). Finally, four rats that had been injected $60 \mathrm{~d}$ previously in the caudate with UV-irradiated AdRL wcrc injcetcd subcutancously with normal AdRL $\left(5 \times 10^{7} \mathrm{pfu}\right)$. After survival for various lengths of time, animals were anesthetized with ether and perfused transcardially with heparinized saline. Brains were removed and frozen in Tissue-Tek OCT (Miles, Elkhart, IN).

To determine whether damage to the brain was a factor in the inflammatory reaction, transections of the right optic nerve were performed on a second group of rats $7 \mathrm{~d}$ after footpad injections, as shown in Table 2 . In albino rats, sectioning the right optic nerve causes Wallerian degeneration predominantly in the left optic tract, lateral geniculate nucleus, and superior colliculus (Lund, 1965). After anesthesia with hypnorm and
Table 2. Optic nerve transections

\begin{tabular}{|c|c|c|c|c|}
\hline & \multirow{2}{*}{$\begin{array}{l}\text { Caudate } \\
\text { injection on } \\
\text { day }-60\end{array}$} & \multirow{2}{*}{$\begin{array}{l}\text { Footpad } \\
\text { injection } \\
\text { on day } 0\end{array}$} & \multicolumn{2}{|c|}{$\begin{array}{l}\text { Number of rats } \\
\text { killed on day: }\end{array}$} \\
\hline & & & 14 & 21 \\
\hline \multirow{3}{*}{$\begin{array}{l}\text { Experimental } \\
\text { Controls }\end{array}$} & AdRL & AdRL & 2 & 3 \\
\hline & none & AdRL & 2 & 2 \\
\hline & none & buffer & 2 & 1 \\
\hline
\end{tabular}

Rats, some of which had been injected previously with AdRL in the right caudate, were injected in the footpad with AdRL or buffer. On day 7 , all rats had transections of the right optic nerve, and the animals were killed on day 14 or 21 .

hypnovel, a vertical incision was made $1 \mathrm{~cm}$ posterior to the lateral palpebral angle exposing the facial vein and superior branches of the facial nerve, which were cauterized and divided, respectively. The anterior fibers of the temporalis muscle were removed to access the lateral orbit, and the lateral rectus muscle was divided and periorbital adipose tissue removed. The optic nerve was sectioned 1-2 mm behind the globe. Complete lesioning was confirmed by visualization of the distal nerve stump with the globe adducted.

Immunocytochemistry. Twenty micrometer coronal sections were cut on a cryostat and collected on glass slides at regular intervals throughout each brain. In addition, serial $10 \mu \mathrm{m}$ sections were collected through an injection site in the caudate, at the level of the substantia nigra, and occasionally in other areas. Sections were fixed in cold ethanol for $10 \mathrm{~min}$, treated with hydrogen peroxide, and blocked with $1.5 \%$ goat serum (for $\beta$-galactosidase localization) or rabbit serum (for other antibodies) in PBS. $\beta$-Galactosidase immunocytochemistry was performed on $20 \mu \mathrm{m}$ sections using a rabbit polyclonal antibody $\left(5^{\prime} 3^{\prime}\right.$, Inc., Bishop's Stortford, UK) at 1:1500 in PBS with 0.1\% Triton X-100 (BDH Chemicals, Lutterworth, UK). The secondary was biotinylated goat anti-rabbit and was detected with the ABC horseradish peroxidase (HRP) method (Vector, Bretton, UK). Additional $20 \mu \mathrm{m}$ sections were immunostained with the mouse monoclonal OX-18 against rat MHC class I (Fukumoto et al., 1982). Secondary antibody was $2 \%$ rabbit anti-mouse/HRP (Dako, High Wycombe, UK) absorbed with $5 \%$ rat serum.

The groups of $10 \mu \mathrm{m}$ serial sections were stained with various mouse anti-rat monoclonal antibodies: OX-18 or OX-6 (MHC class I or II, respectively; Fukumoto et al., 1982), R73 ( $\alpha \beta$ T cell receptor; Hünig et al., 1989), OX-42 (complement receptor type 3 on microglia and macrophages; Robinson et al., 1986), ED1 (macrophages and activated microglia; Dijkstra et al., 1985; Bauer et al., 1994), OX-39 (CD25, the highaffinity IL-2 receptor on activated T cells; Paterson et al., 1987), OX-40 (activated CD4-positive T cells; Paterson et al., 1987), OX-62 (dendritic cells and $\gamma \delta$ T cells; Brenan and Puklavec, 1992), and V65 ( $\gamma \delta$ T cell receptor; Kühnlein et al., 1994). ED1 was obtained as ascites from Serotec (Kidlington, UK), and V65 was obtained as ascites from PharMingen (Cambridgc, UK). All other monoclonal antibodies were generously provided by the MRC Cellular Immunology Unit (Oxford, UK) and used as tissue culture supernatants. Secondary antibody was rabbit antimouse/HRP with rat serum as above. After developing in diaminobenzidine (Sigma, Poole, UK), sections were counterstained with cresyl violet, dehydrated, cleared, and mounted. Control sections that omitted the primary antibody were consistently negative. Some sections were stained with luxol fast blue for localization of myelin and counterstained with cresyl violet.

\section{RESULTS}

\section{Distribution of $\boldsymbol{\beta}$-galactosidase expression}

Rats were given stereotaxic caudate injections of AdRL, an adenovirus vector that expresses $\beta$-galactosidase, and the brains were examined $3 \mathrm{~d}$ later. $\beta$-Galactosidase immunoreactivity was found in and around the injection site in the right caudate and adjacent to major blood vessels in the caudate and, less frequently, the ventral striatum (Fig. $1 A$ ). There were immunopositive cells along the needle track in the cortex and frequent cells spread in a zone in the corpus callosum centered around the needle track. This pattern of spread along the white matter and along the perivascular spaces of blood vessels in the gray matter is similar to that 


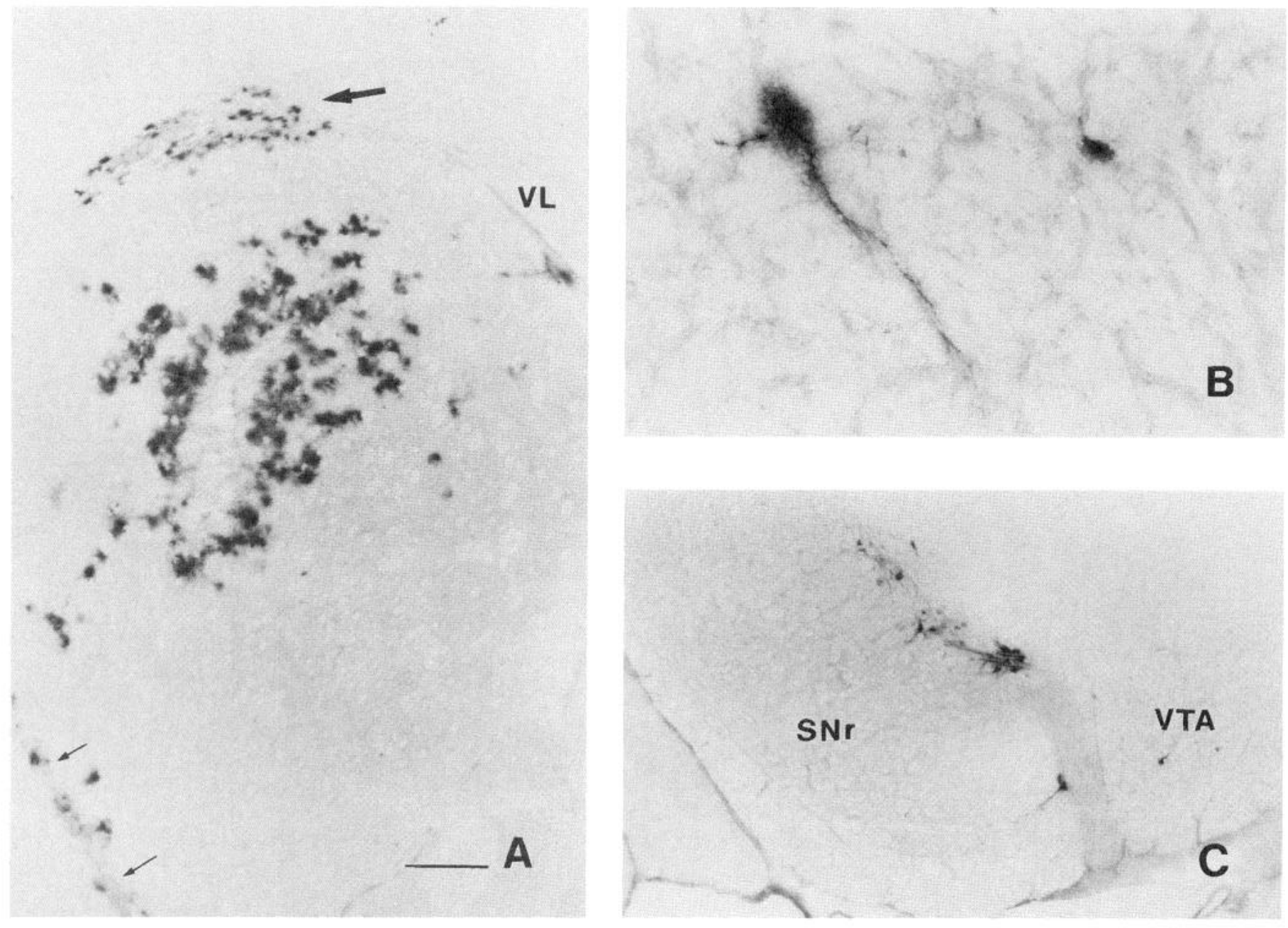

Figure 1. $\beta$-Galactosidase expression $3 \mathrm{~d}$ after an injection of AdRL into the right caudate nucleus. $A$, Numerous $\beta$-galactosidase-positive cells were seen surrounding the injection site in the caudate. In addition, positive cells were found in the corpus callosum (large arrow) and along blood vessels. The anterior striate artery is indicated by small arrows. $V L$, Lateral ventricle. $B$, Two $\beta$-galactosidase-positive cells, one of which is clearly a neuron, are shown in the ipsilateral entopeduncular nucleus (medial globus pallidus). $C$, Many positive neurons were seen in the ipsilateral substantia nigra, mostly in the pars compacta. $S N r$, Substantia nigra pars reticulata; $V T A$, ventral tegmental area. Scale bars, $A, 500 \mu \mathrm{m} ; B, 85 \mu \mathrm{m} ; C, 350 \mu \mathrm{m}$.

seen after injection of other particulate substances into the caudate (Zhang et al., 1992).

In addition, $\beta$-galactosidase-positive cells were found in brain areas with known neuronal projections to the caudate. Rostral to the injection site, numerous immunopositive cells were found scattered throughout the ipsilateral and contralateral frontal cerebral cortex, particularly in motor areas (not shown). Caudal to the injection site, immunopositive cells were found in the ipsilateral globus pallidus and entopeduncular nucleus (Fig. $1 B$ ), areas with a little studied projection to the caudate (Takada and Hattori, 1987). Some of these cells were clearly identifiable as neurons. However, some $\beta$-galactosidase immunoreactivity was also seen in perivascular locations, so it seems likely that virus also reached the globus pallidus and entopeduncular nucleus by spread along perivascular spaces. Occasional cells were seen in the ipsilateral thalamus, particularly in the intralaminar nuclei, and more ventrally in the zona incerta (not shown). More caudally, immunoreactive neurons were found concentrated in the ipsilateral substantia nigra pars compacta and ventral tegmental area, with scattered cells in the substantia nigra pars reticulata (Fig. $1 C$ ). A majority of cells were in the medial substantia nigra pars compacta. $\beta$-Galactosidase-positive cells continued caudally into the retrorubral field of the mesencephalic reticular nucleus, which contains the A8 group of dopaminergic neurons. No positive cells were seen in the amygdala, dorsal raphe, or locus coeruleus, all of which project to the caudate.

\section{Inflammation in control animals}

In agreement with previous results, rats killed $60 \mathrm{~d}$ after injection of adenovirus vector into the caudate showed continued, although reduced, expression of $\beta$-galactosidase and little inflammation (Byrnes et al., 1995). As controls, rats with previous injections of AdRL in the caudate were injected subcutaneously with various substances and killed 2 weeks later. No increased inflammation in the caudate or decrease in $\beta$-galactosidase expression was seen after rats were injected subcutaneously with buffer or with nonreplicating HSV-1, regardless of whether the HSV expressed $\beta$-galactosidase.

In all of these controls, fewer $\beta$-galactosidase-positive cells were seen in the caudate and corpus callosum than had been found at $3 \mathrm{~d}$ after the injection (Fig. $2 A$ ), and $\beta$-galactosidase was only occasionally detected in other brain areas, most frequently in neurons of the ipsilateral substantia nigra pars compacta. The injection site had a scar-like area with slightly elevated MHC I expression (Fig. $2 B$ ) and scattered MHC II-expressing cells and ED1-positive macrophages. Microglia expressed elevated levels of 

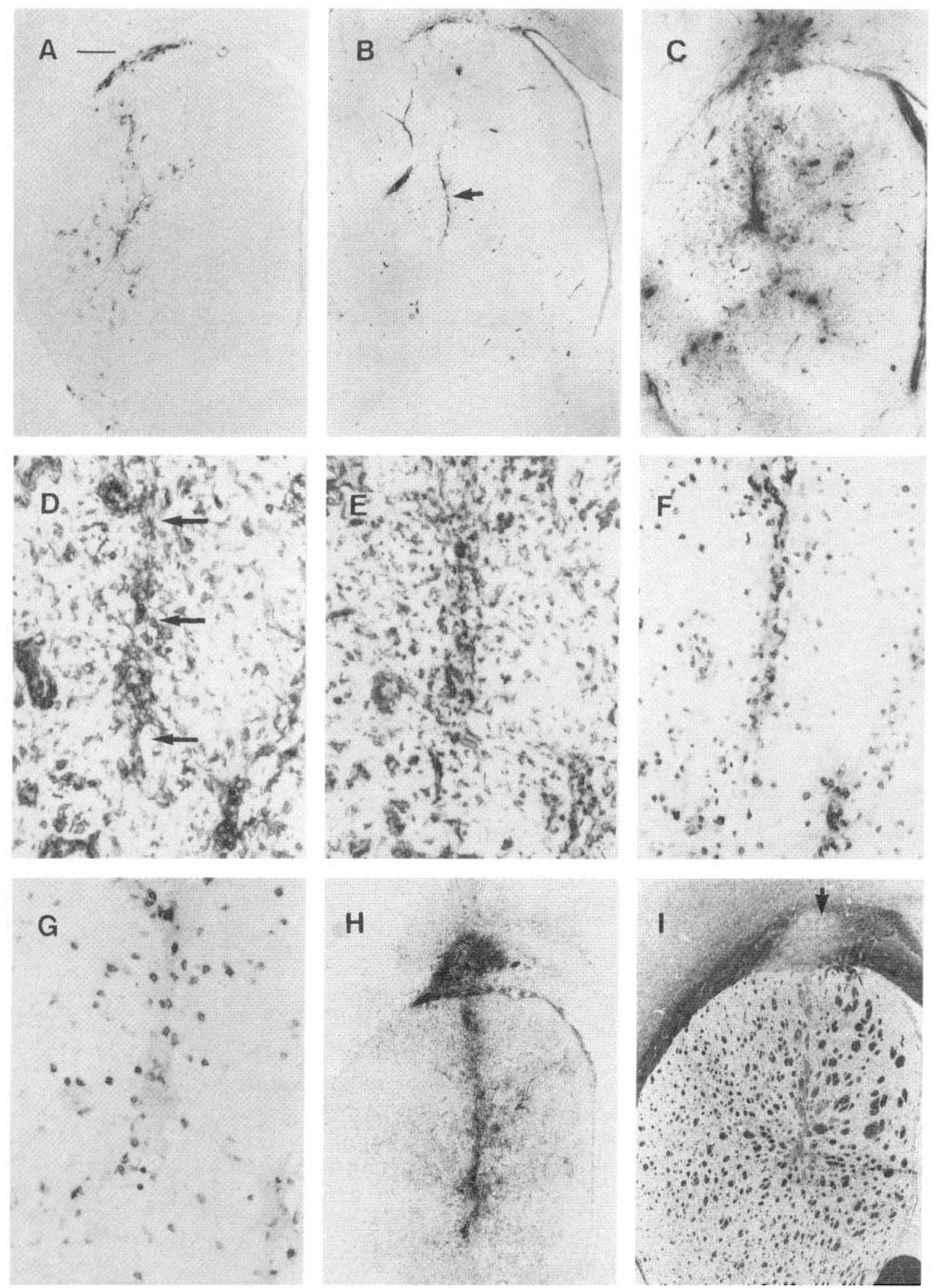

Figure 2. Reaction in the brain after peripheral exposure to AdRL. $A$, Sixty days after injection of AdRL into the caudate, many $\beta$-galactosidaseexpressing cells were still seen in the caudate and corpus callosum. $B$, Little MHC I expression was seen at $60 \mathrm{~d}$ in the caudate. The injection site is marked by an arrow. MHC I is also seen on vascular endothelium, the ventricular ependyma, and some microglia. $C$, After a peripheral injection of AdRL into rats that had previously received AdRL in the caudate, MHC I expression was greatly upregulated in the caudate, shown here 3 weeks after the peripheral injection. This was accompanied by many perivascular cuffs containing MHC I-positive leukocytes. $D$, Expression of MHC II was seen on infiltrating leukocytes in the injection tract (arrows), in nearby perivascular cuffs, and on microglia. Panels $D-G$ are taken from an animal killed 2 weeks after the peripheral AdRL injection. E, ED1-positive macrophages were seen in perivascular cuffs and in the parenchyma, as well as ED1-positive cells with microglial morphology. $F$, Many T cells expressing the $\alpha \beta$ T cell receptor were seen in the cuffs and in the parenchyma. $G$, Numerous OX-62-positive cells were also found. These were most likely dendritic cells. $H$, Expression of OX-42, an antigen expressed on macrophages and activated microglia, is shown 4 weeks after a peripheral injection of AdRL. $I$, In a nearby section from the same animal, staining with luxol fast blue reveals severe demyelination in areas of inflammation. An arrow indicates demyelination in the corpus callosum. Scale bar: $A-C, H, I, 420 \mu \mathrm{m} ; D-G, 53 \mu \mathrm{m}$. 
Table 3. Brain areas showing inflammation after a footpad injection of AdRL

Days after footpad injection

\begin{tabular}{lllllllllllllllllll}
\hline $\mathrm{A}$ & $\mathrm{B}$ & $\mathrm{C}$ & $\mathrm{D}^{a}$ & $\mathrm{E}^{a}$ & & $\frac{21}{\mathrm{~A}}$ & $\mathrm{~B}$ & $\mathrm{C}$ & $\mathrm{D}$ & $\mathrm{E}^{a}$ & $\mathrm{~F}^{a}$ & $\mathrm{G}^{a}$ & & & $\frac{28}{\mathrm{~A}}$ & $\mathrm{~B}$ & $\mathrm{C}$ & $\mathrm{D}$ \\
\hline
\end{tabular}

Frontal cerebral cortex

Ipsilateral

Contralateral

Caudate (injection site)

Globus pallidus, ipsilateral

Amygdala, ipsilateral

Thalamus, ipsilateral

Substantia nigra/ventral tegmental nucleus

Ipsilateral

Contralateral

Dorsal raphe

Locus coeruleus

Ipsilateral

Contralateral

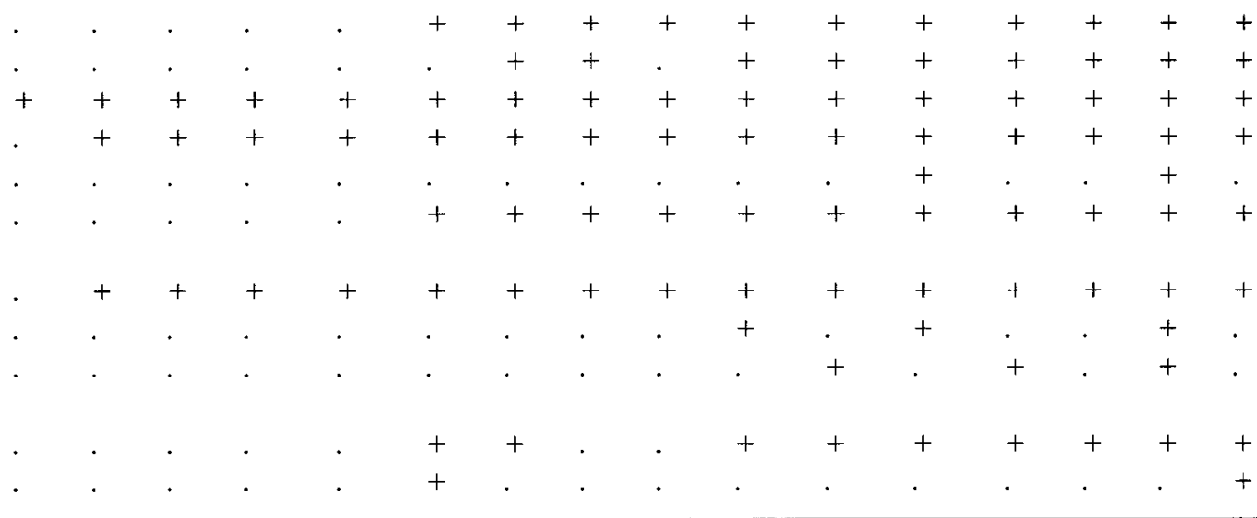

Two months before a footpad injection of AdRL, rats had received AdRL injections into the right caudate. For each rat, brain areas showing upregulation of MHC I on microglial cells and infiltration of MHC I-positive round cells are marked as positive. Most of these areas also showed perivascular cuffing.

${ }^{a}$ These rats, as part of a separate experiment, received a transection of the right optic nerve on day 7 after the footpad injection of AdRL.

OX-42 relative to the contralateral caudate, and in some animals microglia expressing MHC I and MHC II were found immediately around the injection site and in the corpus callosum. Very few OX-62-positive cells and no V65-positive $\gamma \delta \mathrm{T}$ cells were seen. Some animals had scattered R73-positive $\mathrm{T}$ cells in the injection site and in the corpus callosum, and occasionally a large blood vessel was found with substantial numbers of perivascular 'I' cells. These $\mathrm{T}$ cells only occasionally expressed the high-affinity IL-2 receptor (OX-39) or the CD4-positive $\mathrm{T}$ cell activation marker OX-40. Staining for myelin revealed no areas of demyelination. Except for the occasional blond vessel with elevated numbers of perivascular cells, vascular endothelium expressed similar low levels of MHC I as on blood vessels in other areas of the brain and had similar numbers of perivascular ED1-positive cells.

Other than in the caudate, little expression of MHC I was seen on parenchymal cells in any brain area of control rats. The ipsilateral substantia nigra was examined carefully; with the exception of one rat that had a small focal patch of $T$ cells and activated microglia in the pars compacta, microglia were normal and no excess expression of MHC I or II was found. R73-positive $T$ cells were infrequently seen, and ED1-positive macrophages appeared to be mainly perivascular, as in other areas of the brain.

\section{Peripheral reactivation of the immune response}

Rats that had been injected in the caudate with AdRL $60 \mathrm{~d}$ previously were injected in the footpad with AdRL. Preliminary experiments indicated that no excess inflammation or leukocyte recruitment could be seen in the caudate $9 \mathrm{~d}$ after the footpad injection, with $\beta$-galactosidase expression remaining similar to that in controls (not shown). We therefore examined animals at 2 , 3 , and 4 weeks after the footpad injection of vector. All animals killed on or after $14 \mathrm{~d}$ had greatly elevated OX-42, MHC I, and MHC II expression in the caudate as well as substantial perivascular cuffing and parenchymal infiltration of $\mathrm{T}$ cells and ED1positive macrophages (Fig. $2 C, H$ ). Microglia expressing intense $\mathrm{MHC}$ I and MHC II were spread widely through the caudate, and some ED1-positive cells with microglial morphology were also seen close to the original injection site (Fig. $2 D, E$ ). Many acti- vated T cells (OX-39-positive or OX-40-positive) were found in perivascular cuffs and in the parenchyma, although these were always fewer that the total number of R73-positive T cells (Fig. $2 F$ ). In addition, many OX-62-positive cells were seen in cuffs and in the parenchyma (Fig. $2 G$ ). Although this antigen is expressed on both dendritic cells and $\gamma \delta \mathrm{T}$ cells, only scattered V65-positive $\gamma \delta \mathrm{T}$ cells could be found on nearby sections (not shown), indicating that a vast majority of OX-62-positive cells were dendritic cells. Polymorphonuclear cells were rarely seen.

One rat with relatively mild inflammation at $14 \mathrm{~d}$ (Table 3,14A) still had substantial numbers of $\beta$-galactosidase-expressing cells in the caudate. However, the other two rats in this group (14B and 14C) had severe inflammation and only occasional $\beta$-galactosidase-positive cells could be found. Similar inflammation in the caudate and greatly decreased $\beta$-galactosidase expression were seen in all animals on days 21 and 28 , and rare $\beta$-galactosidase-expressing cells were found in only a minority of brains.

Intense inflammation in restricted areas of the corpus callosum was also found from $14 \mathrm{~d}$ onward (Fig. $2 \mathrm{H}$ ), in a distribution similar to that found for $\beta$-galactosidase in control animals. As in the caudate, this inflammation included large numbers of $T$ cells (some of them activated) and many ED1-positive macrophages and OX-62-positive cells. At $14 \mathrm{~d}$, sections stained histologically for myelin occasionally showed myelin pallor, but by days 21 and 28 most animals had a total lack of myelin in these restricted areas (Fig. 2I). Myelin pallor and demyelination were also seen in some of the white matter bundles coursing through the caudate immediately adjacent to the injection site.

A comparable inflammatory response and drop in $\beta$-galactosidase expression were found in rats injected in the caudate with AdRL, then subcutaneously injected $60 \mathrm{~d}$ later with a non-lacZ-containing adenovirus vector (not shown). Together with the fact that HSV-1 $1803-$ lacZ was unable to trigger an inflammatory attack on persisting AdRL in the brain, this indicates that most of the inflammation was probably directed against adenovirus proteins rather than against $\beta$-galactosidase. 
Another group of rats was injected in the caudate with AdRL that had been UV-irradiated to inactivate RNA transcription. Sixty days later, they were injected in the footpad with normal AdRL. These animals showed no elevated levels of inflammation in the caudate or in any other brain area up to $28 \mathrm{~d}$ after the footpad injection, indicating that the ability to reactivate an immune response in the original injection site was contingent upon adenovirus vector gene expression in the brain.

\section{Inflammation in afferent areas}

Brains were sectioned from the frontal cortex to just past the locus coeruleus in the brainstem and examined for inflammation and elevated expression of MHC I. From $14 \mathrm{~d}$ onward, a pattern of increasing inflammation, perivascular cuffing and upregulation of MHC I on microglia could be seen in areas known to contain neurons projecting to the caudate (Table 3). The earliest inflammation was seen in the ipsilateral substantia nigra/ventral tegmental area and in the ipsilateral globus pallidus/entopeduncular nucleus (Fig. $3 B, E$ ). As noted above, vector may have originally entered the globus pallidus and entopeduncular nucleus by spread from the injection site, so inflammation in these two areas is probably not a response to retrogradely transported vector alone. At 21 and $28 \mathrm{~d}$ after the footpad injection, additional inflammation was seen bilaterally in the frontal cerebral cortex and ipsilaterally in the thalamus and retrorubral area of the mesencephalic reticular nucleus (Fig. $3 A, C, D$ ). There were also small areas of inflammation that were found inconsistently in other arcas throughout the cerebral cortex. At 21 and $28 \mathrm{~d}$, inflammation was also frequently seen in the ipsilateral locus coeruleus but less frequently and with less intensity on the contralateral side (Fig. $3 F$ ). Inflammation was only occasionally seen in the dorsal raphe or amygdala (basolateral nucleus). In some animals, a slight amount of inflammation was seen in the contralateral caudal substantia nigra pars compacta, consistent with the small contralateral projection from these neurons (Douglas et al., 1987). The exact brain areas showing inflammation varied somewhat from animal to animal (Table 3).

The inflammation in the ipsilateral substantia nigra and ventral tegmental area was examined in detail and found to be similar to that in the caudate. There were large numbers of mononuclear cells in the substantia nigra pars compacta and ventral tegmental area, with a less dense infiltrate in the substantia nigra pars reticulata (Fig. 4A-D). Numcrous blood vesscls with largc perivascular cuffs of mononuclear cells were seen. Elevated expression of OX-42, MHC II, and ED1 was seen on cells with microglial and macrophage morphology, with the highest expression in the substantia nigra pars compacta and ventral tegmental area (Fig. $4 A, B$ ). MHC I was elevated on brain cells, infiltrating mononuclear cells, vascular endothelium, and perivascular cells. Numerous R73-positive T cells were seen, but smaller numbers of OX-39-positive and OX-40-positive cells were found, indicating that both activated and unactivated $T$ cells were present (Fig. $4 C, D)$. Numerous OX-62-positive cells were also found, both in perivascular cuffs and in the parenchyma. As in the caudate, very few $\gamma \delta \mathrm{T}$ cells were seen, indicating that most of the OX-62positive cells were dendritic cells.

Detailed examinations of the inflammation in the ipsilateral thalamus and bilateral prefrontal cerebral cortex of selected rats at 21 or $28 \mathrm{~d}$ were in all respects similar.

\section{Specificity of the inflammation}

Because $\beta$-galactosidase-positive cells had not been found consistently in every brain area with projections to the caudate, and because few such cells could be found by 2 months after the injection, we wished to determine whether the inflammation in these afferent sites was caused by the continued presence of vector or vector antigens in these areas, or whether it was instead a nonspecific consequence of inflammatory damage in the caudate. Although $\mathrm{T}$ cell accumulation is not normally seen in the brain in the absence of an antigen-specific response (Hickey et al., 1991), it is conceivable that autoreactive $\mathrm{T}$ cells specific for brain antigens might have developed during the immune response to the virus (Watanabe et al., 1983). In this case, autoreactive $T$ cells would be able to localize to sites of retrograde neuronal damage, as has been shown previously (Maehlen et al., 1989).

Although Wallerian degeneration caused by transection of the optic nerve leads to microglial proliferation and upregulation of MHC in the optic tract and its targets, the lateral geniculate nucleus and superior colliculus, it does not normally cause perivascular cuffing or noticeable recruitment of hematogenous cells (Rao and Lund, 1989; Lawson et al., 1994). However, if an optic nerve transection is combined with an ongoing anti-brain $\mathrm{T}$ cell response, perivascular cuffing and leukocyte recruitment are then seen in areas of Wallerian degeneration (Konno et al., 1990; Molleston et al., 1993). We reasoned that if the T cell recruitment and other inflammation that we saw in caudate afferents was a nonspecific consequence of degeneration or a result of an autoimmune reaction, we would also see such inflammation in brain areas with ongoing Wallerian degeneration.

Rats that had been injected in the right caudate with AdRL $60 \mathrm{~d}$ previously were injected in the footpad with AdRL (day 0), and then had their right optic nerve transected on day 7 (see Table 2). They were killed on day 14 or 21 . As expected, there was upregulation of MHC I, MHC II, and OX-42 on microglia in areas of Wallerian degeneration, most obviously in the optic tract and superior colliculus contralateral to the optic nerve transection (Fig. 5A). In the superior colliculus, MHC II and ED1 were expressed most highly in the striatum opticum, in agreement with previous results (Rao and Lund, 1989). There were also ED1positive cells in the optic tract and superior colliculus (Fig. 5B), some of which had identifiable microglial morphology. All of these microglial markers, however, were expressed at lower levels in areas of Wallerian degeneration than they were in the inflamed substantia nigra. In addition, areas of Wallerian degeneration contained no perivascular cuffs and no elevated numbers of R73positive T cells or OX-62-positive dendritic cells. Blood vessels passing through these areas appeared completely normal.

As expected, the inflammation in areas capable of retrogradely transporting vector from the caudate was similar to that seen in rats without Wallerian degeneration (Table 3). Control animals that had received no caudate injection (Table 2) showed a similar microglial reaction to Wallerian degeneration in the optic tract and superior colliculus, but had no perivascular cuffing or inflammation anywhere in the brain.

\section{DISCUSSION}

\section{Vulnerability of persisting antigens in the brain}

A variety of experiments has demonstrated that many foreign antigens can persist in the brain parenchyma for long periods of time, often without chronic inflammation. A neural graft from a donor with mismatched histocompatibility antigens can frequently survive in the brain despite the fact that the same tissue, if placed in the periphery, would be destroyed by the immune system (Sloan et al., 1991). Likewise, mycobacterial antigens, when injected into the brain, are able to persist for months in the absence 

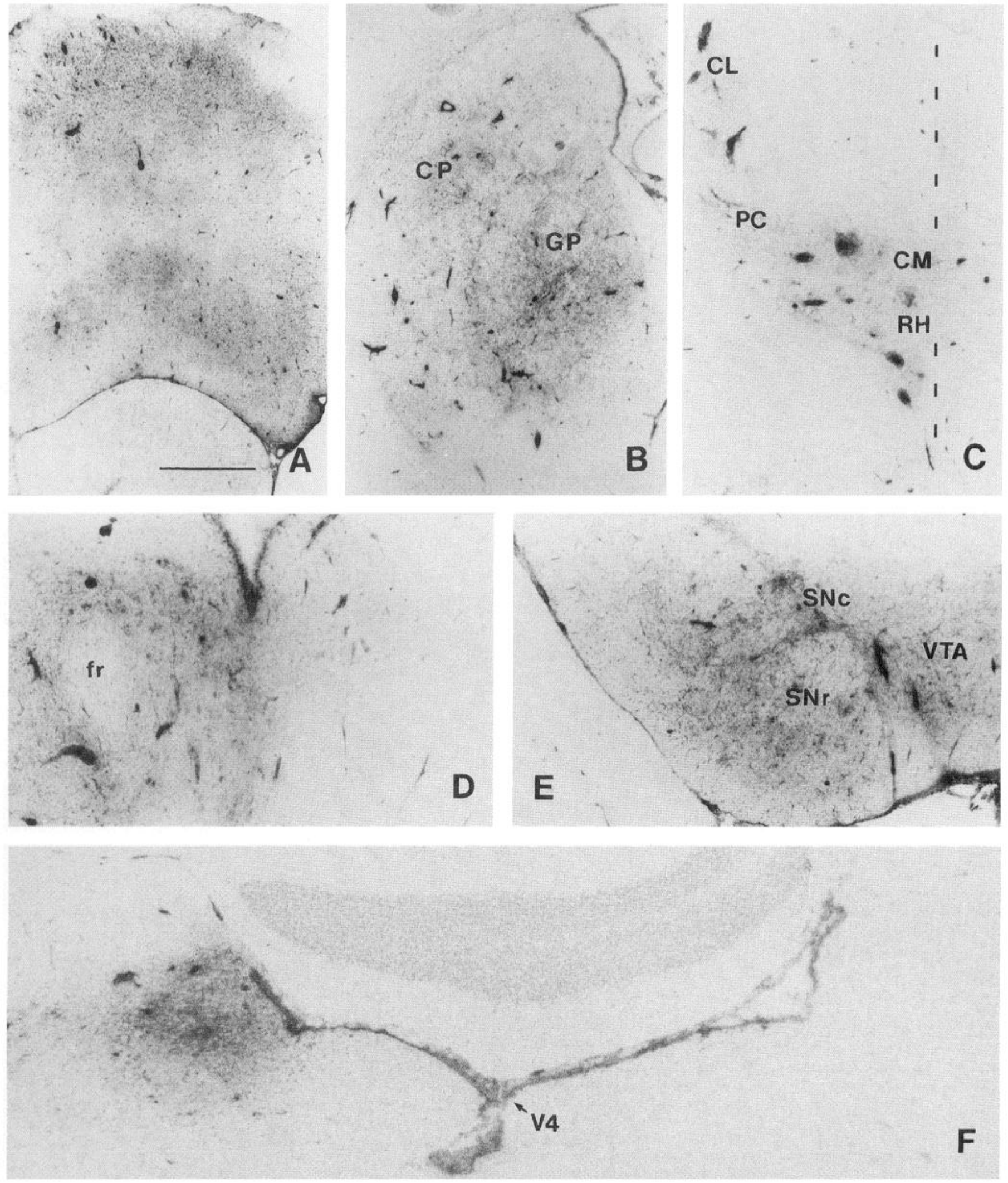

Figure 3. MHC I expression in afferents to the caudate. $A$, Contralateral frontal cerebral cortex (mainly secondary motor areas) at 4 weeks after peripheral exposure to AdRL. Note the numerous MHC I-positive perivascular cuffs. $B$, Ipsilateral globus pallidus $(G P)$ and caudal caudate putamen ( $C P$ ) at 3 weeks. $C$, Ipsilateral thalamus at 4 weeks; inflammation is seen in the rostral intralaminar nuclei. The midline is indicated. $R H$, Rhomboid nucleus; $C M$, central median; $P C$, paracentral; $C L$, central lateral. $D$, Ipsilateral thalamus: parafascicular nucleus at 3 weeks. Note lack of inflammation on the contralateral side. $f r$, Fasciculus retroflexus. $E$, Ipsilateral substantia nigra at 3 weeks. $S N c$, Pars compacta; $S N r$, pars reticulata; $V T A$, ventral tegmental area. $F$, Ipsilateral locus coeruleus at 4 weeks. No inflammation is seen in the contralateral locus coeruleus. $V 4$, Fourth ventricle. Scale bar: $A, B, 1$ mm; $C-E, 500 \mu \mathrm{m} ; F, 390 \mu \mathrm{m}$. 

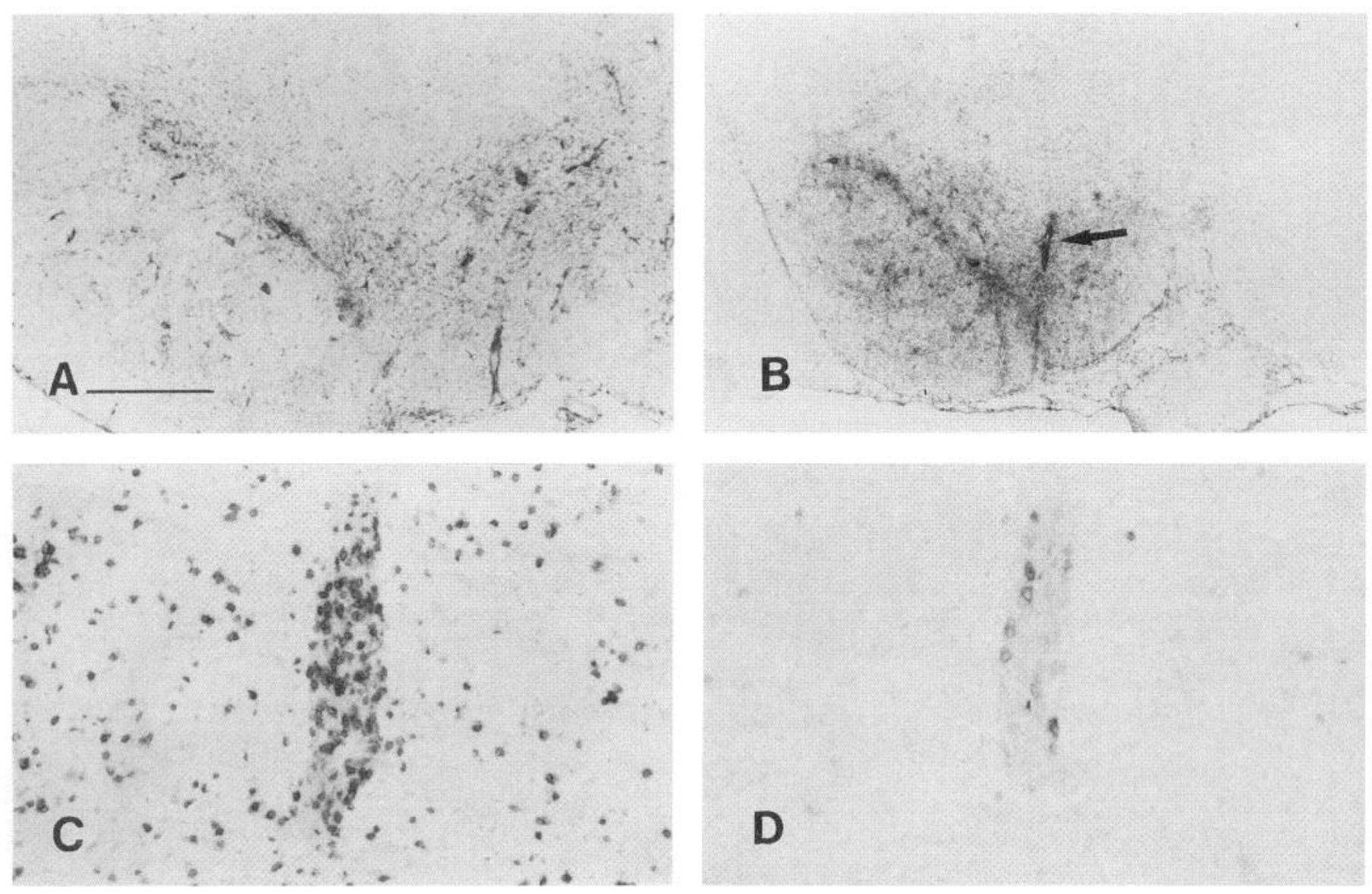

Figure 4. Inflammation in the ipsilateral substantia nigra. $A$, MHC II expression at 4 weeks after peripheral exposure to AdRL. $B$, OX-42 expression at 3 weeks. No inflammation is seen on the contralateral side of the brain. The blood vessel indicated with an arrow is shown stained with other monoclonal antibodies in $C$ and $D . C$, T cells that express the $\alpha \beta$ T cell receptor. Note their presence both in the perivascular cuff and in the parenchyma of the brain. $D$, A nearby section stained with OX-39, which detects the high-affinity IL-2 receptor, which is present on activated T cells, indicates that most of the T cells are not activated. Staining with OX-40 found similar small numbers of cells (not shown). Scale bar: $A, 500 \mu \mathrm{m} ; B, 1 \mathrm{~mm} ; C, D, 125 \mu \mathrm{m}$.

of inflammation (Matyszak and Perry, 1995). In both of these cases of persisting antigen, however, peripheral exposure to the same foreign antigen results in activation of specific $\mathrm{T}$ cells capable of entering the brain and causing a damaging, local cellmediated response. It seems that, although injecting foreign antigens into the brain is a relatively poor way to initiate a cell-mediated immune response, being in the brain does not necessarily confer much special protection once such a response is initiated.

This applies to adenovirus vectors as well. We have shown previously that the acute inflammation caused by an injection of adenovirus vector into the rat brain gradually diminishes, reaching negligible levels by $1-2$ months later despite the fact that expression of $\beta$-galactosidase and viral protein can still be detected (Byrnes et al., 1995). The present study demonstrates that this persistence is unstable - after a peripheral injection of adenovirus vector, a considerably more severe inflammation is reinitiated in the brain. This immune response is sufficient to almost completely abolish detectable $\beta$-galactosidase expression. In organs other than the brain, it appears that antigenspecific cytotoxic $\mathrm{T}$ cells eliminate vector-transduced cells (Yang et al., 1994, 1995). Further study will be needed to determine whether vector-transduced brain cells are being killed by lymphocytes. Alternative possibilities include shutdown of $\beta$-galactosidase expression or elimination of vector DNA by noncytotoxic mechanisms.
It is important to note that the immunological privilege enjoyed by foreign antigens in the brain is relative, not absolute. Grafts of neural tissue are rejected, for instance, if the histocompatibility difference is very large, as in xenografts (Mason et al., 1986). We have found that adenovirus vectors can cause a more severe and persistent inflammatory response in the brain if they are injected in larger amounts, although this does not necessarily result in the disappearance of marker protein expression (K. Kajiwara, A. Byrnes, H. Charlton, M. Wood, and K. Wood, unpublished observations).

As previously demonstrated by Matyszak and Perry (1995) and now confirmed with adenovirus vectors, the inflammation resulting from a peripherally activated immune response to a persisting antigen in the brain can be so severe that it results in demyelination. It remains to be determined whether this is a result of direct cytotoxic attack of vector-specific T cells on transfected oligodendrocytes, "bystander" damage to myelin caused by toxic substances from inflammatory cells (Selmaj et al., 1991; Merrill et al., 1993), or secondary demyelination caused by focal destruction of axons. Regardless of the exact mechanism, this provides evidence that persisting virus or viral antigens can remain the target of a damaging immune response long after their original entrance into the brain, even in the complete absence of replication. This finding may be helpful in understanding the immunopathology of certain viral infections of the human brain. 

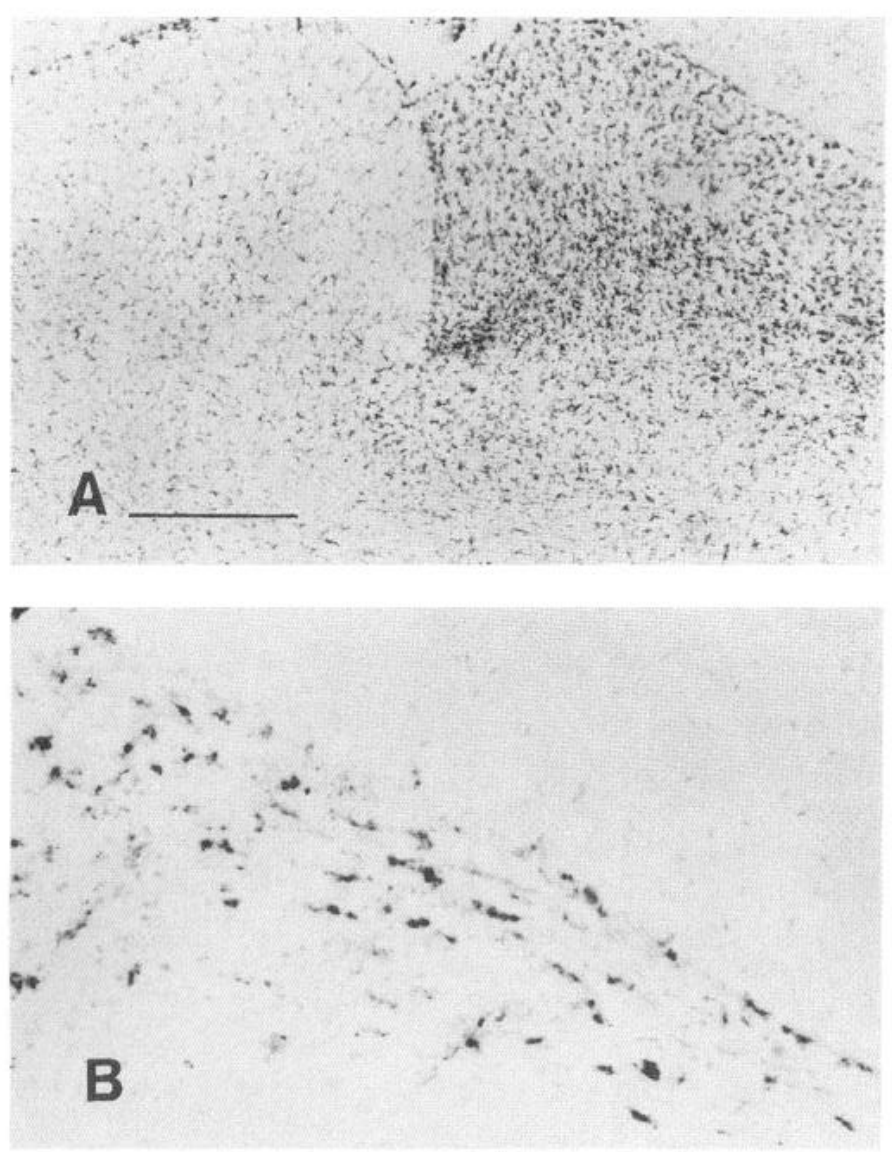

Figure 5. Microglial activation caused by Wallerian degeneration of the optic nerve. $A, \mathrm{OX}-42$ expression in the superior colliculus was upregulated 1 week after sectioning the optic nerve. No excess expression is seen on the other side of the brain, which is innervated by the uncut optic nerve. $B$, ED1 upregulation in the optic tract, shown at 2 weeks after optic nerve transection. Scale bar: $A,=500 \mu \mathrm{m} ; B, 125 \mu \mathrm{m}$.

\section{Inflammation in afferent sites}

After injection of AdRL into the caudate, numerous $\beta$-galactosidase-positive cells were seen in major afferent areas, most notably the ipsilateral substantia nigra pars compacta/ventral tegmental area and the bilateral prefrontal cortex (Veening et al., 1980; McGeorge and Faull, 1989). Positive cells were also seen in the ipsilateral globus pallidus and entopeduncular nucleus (Takada and Hattori, 1987), with fewer cells in the ipsilateral thalamus (Jones and Leavitt, 1974; Berendse and Groenewegen, 1990). We did not see $\beta$-galactosidase-positive neurons in the dorsal raphe, locus coeruleus, (Pasquier et al., 1977), or amygdala (Kita and Kitai, 1990). However, it must not be assumed that $\beta$-galactosidase will necessarily be detectable in every neuron that retrogradely transports the vector. The RSV promoter has shown strong tissue specificity in transgenic mice (Overbeek et al., 1986), and could conceivably express better in some neural types than others. In particular, we noted that $\beta$-galactosidase immunoreactivity in cortical and thalamic neurons was much weaker than that in the substantia nigra.

We saw severe mononuclear inflammation in afferents to the caudate after peripheral activation of the immune response, including many $\mathrm{T}$ cells. This would seem to indicate a vector-specific $\mathrm{T}$ cell response-although activated $\mathrm{T}$ cells readily enter the brain without regard to antigen specificity, they do not accumulate unless they encounter the correct antigen presented by MHC (Wekerle et al., 1986; Hickey et al., 1991; Ludowyk et al., 1992).

The accumulation of $T$ cells in afferents to the caudate cannot be explained by retrograde damage or death of afferent neurons. A variety of studies on anterograde, retrograde, and excitotoxic damage to distant axons or neurons has consistently failed to find perivascular cuffing, substantial numbers of $\mathrm{T}$ cells, or even hematogenously derived macrophages in damaged areas (Graeber et al., 1990; Töpper et al., 1993; Lawson et al., 1994). Even when such damage is combined with a strong ongoing $\mathrm{T}$ cell response to an irrelevant antigen, no accumulation of $\mathrm{T}$ cells is seen. For instance, after facial nerve transection and peripheral immunization with complete Freund's adjuvant, no accumulation of T cells is seen in the facial nerve nucleus (Maehlen et al., 1989).

During a reaction against brain self-antigen, however, $T$ cells do accumulate in areas of retrograde and anterograde damage (Maehlen et al., 1989; Konno et al., 1990; Molleston et al., 1993). Autoimmune $\mathrm{T}$ cell responses can develop during viral infections of the brain (Watanabe et al., 1983) or even after nerve damage (Olsson et al., 1992). We therefore tested whether an anti-brain response could be responsible for the $\mathrm{T}$ cell recruitment to caudate afferents that we observed.

In animals with an autoimmune, anti-brain $\mathrm{T}$ cell response, Wallerian degeneration caused by severing the optic nerve is known to cause recruitment of $\mathrm{T}$ cells to degenerating areas (Konno et al., 1990; Molleston et al., 1993). Using this paradigm, we found no inflammatory response and no accumulation of $\mathrm{T}$ cells in areas of Wallerian degeneration, while intense inflammation was occurring at the same time in caudate afferents. This rules out autoimmunity as an explanation.

This leads to the conclusion that the inflammation in afferent sites is most likely a specific response to vector that has been retrogradely transported by neurons from the caudate. This is of importance because it is currently unclear whether neurons can present antigens to T cells. Although there is now strong evidence that they can express MHC I and $\beta_{2}$-microglobulin under certain circumstances in vitro (Neumann et al., 1995), neurons may also lack other proteins necessary for antigen presentation (Joly and Oldstone, 1992). CD8-positive T cells have been shown, however, to be important in limiting replication of retrogradely transported HSV-1, raising the possibility that neurons might present antigen to $\mathrm{T}$ cells in vivo (Pereira et al., 1994).

There are alternative possibilities, however, other than direct antigen presentation by neurons. For instance, some neurons in afferent sites might die because of retrograde degeneration after damage to the caudate, and the dead neurons and any adenovirus proteins they contain would be phagocytosed by neighboring microglia, which can remain in the brain for long periods afterward (Rinaman et al., 1991). Adenovirus antigens could then be presented by microglia, which can express both MHC I and MHC II. Our observation of so many OX-62-positive dendritic cells appearing in the brain is also intriguing, because these are known to be very potent antigen-presenting cells. However, the fact that OX-62-positive cells are not normally found in the brain, and do not even enter during Wallerian degeneration (as noted in this report), means that they are unlikely candidates for the initial, local antigen-presenting cell in the brain.

The possibility that adenovirus proteins are expressed on the plasma membrane of neurons in afferent sites and picked up by neighboring antigen-presenting cells is probably unlikely, because the only known surface membrane proteins of human adenovirus type $5,10.4 \mathrm{~K}$ and $14.5 \mathrm{~K}$ (Stewart et al., 1995), have been deleted 
from the E3 region of Ad5 dl309 (Carlin et al., 1989) and, hence, from AdRL.

\section{Implications for gene therapy in the brain}

Three conclusions regarding the use of E1-deleted adenovirus vectors in the brain can be drawn. (1) Even long-lasting expression from these vectors is at risk if the immune response is reactivated. Such vectors could not safely be used in the brains of humans, for instance, because during any subsequent infection with adenovirus, activated anti-viral $\mathrm{T}$ cells might target the persisting vector in the brain. (2) T cells can target retrogradely transported vector and cause severe inflammation in many distant brain areas.

(3) Finally, better adenovirus vectors that express fewer viral genes should be substantially more resistant to immune attack (Engelhardt et al., 1994). After injecting UV-irradiated AdRL (which expresses no genes) into the caudate, we were unable to activate an immune response in the brain with a peripheral exposure to AdRL.

\section{REFERENCES}

Akli S, Caillaud C, Vigne E, Stratford-Perricaudet LD, Poenaru L, Perricaudet M, Kahn A, Pechanski MR (1993) Transfer of a foreign gene into the brain using adenovirus vectors. Nature Genet 3:224-228.

Backes MG, Lund RD, Lagenaur CF, Kunz HW, Gill TJ (1990) Cellular events associated with peripherally induced rejection of mature neural xenografts placed into neonatal rat brains. J Comp Neurol 295:428-437.

Bauer J, Sminia T, Wouterlood FG, Dijkstra CD (1994) Phagocytic activity of macrophages and microglial cells during the course of acute and chronic relapsing experimental autoimmune encephalomyelitis. J Neurosci Res 38:365-375.

Berendse HW, Groenewegen HJ (1990) Organization of the thalamostriatal projections in the rats, with special emphasis on the ventral striatum. J Comp Neurol 299:187-228.

Brenan M, Puklavec M (1992) The MRC OX-62 antigen: a useful marker in the purification of rat veiled cells with the biochemical properties of an integrin. J Exp Med 175:1457-1465.

Byrnes AP, Rusby JE, Wood MJA, Charlton HM (1995) Adenovirus gene transfer causes inflammation in the brain. Neuroscience 66:1015-1024.

Carlin CR, Tollefson AE, Brady HA, Hoffman BL, Wold WSM (1989) Epidermal growth factor receptor is down-regulated by a $10,400 \mathrm{MW}$ protein encoded by the E3 region of adenovirus. Cell 57:135-144.

Davidson BL, Allen ED, Kozarsky KF, Wilson JM, Roessler BJ (1993) A model system for in vivo gene transfer into the central nervous system using an adenoviral vector. Nature Genet 3:219-223.

Dijkstra CD, Döpp EA, Joling P, Kraal G (1985) The heterogeneity of mononuclear phagocytes in lymphoid organs: distinct macrophage subpopulations in the rat recognized by monoclonal antibodies ED1, ED2 and ED3. Immunology 54:589-599.

Douglas R, Kellaway L, Mintz M, van Wageningen G (1987) The crossed nigrostriatal projection decussates in the ventral tegmental decussation. Brain Res 418:111-121.

Engelhardt JF, Ye X, Doranz B, Wilson JM (1994) Ablation of E2A in recombinant adenoviruses improves transgenc persistence and decreases inflammatory response in mouse liver. Proc Natl Acad Sci USA 91:6196-6200

Fukumoto T, McMaster WR, Williams AF (1982) Mouse monoclonal antibodies against rat major histocompatibility antigens. Two Ia antigens and expression of Ia and class 1 antigens in rat thymus. Fur $\mathbf{I}$ Immunol 12:237-243.

Ginsberg HS, Moldawer LL, Sehgal PB, Redington M, Kilian PL, Chanock RM, Prince GA (1991) A mouse model for investigating the molecular pathogenesis of adenovirus pneumonia. Proc Natl Acad Sci USA 88:1651-1655.

Graeber MB, Streit WJ, Kiefer R, Schoen SW, Kreutzberg GW (1990) New expression of myelomonocytic antigens by microglia and perivascular cells following lethal motor neuron injury. J Neuroimmunol 27:121-132.

Hickey WF, Hsu BL, Kimura H (1991) T-lymphocyte entry into the central nervous system. J Neurosci Res 28:254-260.

Hünig T, Wallny HJ, Hartley JK, Lawerzky A, Tiefenthaler G (1989) A monoclonal antibody to a constant determinant of the rat $\mathrm{T}$ cell antigen receptor that induces $T$ cell activation. Differential reactivity with subsets of immature and mature T lymphocytes. J Exp Med 169:73-86.

Joly E, Oldstone MBA (1992) Neuronal cells are deficient in loading peptides onto MHC class I molecules. Newron 8:1185-1190.

Jones EG, Leavitt RY (1974) Retrograde axonal transport and the demonstration of non-specific projections to the cerebral cortex and striatum from thalamic intralaminar nuclei in the rat, cat and monkey. $J$ Comp Neurol 154:349-378.

Jones N, Shenk T (1979) Isolation of adenovirus type 5 host range deletion mutants defective for transformation of rat embryo cells. Cell 17:683-689.

Kass-Eisler A, Falck-Pedersen E, Elfenbein DH, Alvira M, Buttrick PM, Leinwand LA (1994) The impact of developmental stage, route of administration and the immune system on adenovirus-mediated gene transfer. Gene Therapy 1:395-402.

Kita H, Kitai ST (1990) Amygdaloid projections to the frontal cortex and the striatum in the rat. J Comp Neurol 298:40-49.

Konno H, Yamamolo T, Suzuki H, Yamamolo H, Iwasaki $Y$, Ohara $Y$, Terunuma H, Harata N (1990) Targeting of adoptively transferred experimental allergic encephalitis lesion at the sites of Wallerian degeneration. Acta Neuropathol 80:521-526.

Kühnlein P, Park J-H, Herrmann T, Elbe A, Hünig T (1994) Identification and characterization of rat $\gamma / \delta \mathrm{T}$ lymphocytes in peripheral lymphoid organs, small intestine, and skin with a monoclonal antibody to a constant determinant of the $\gamma / \delta \mathrm{T}$ cell receptor. J Immunol 153:979. 986

Lawson LJ, Frost L, Risbridger J, Fearn S, Perry VH (1994) Quantification of the mononuclear phagocyte response to Wallerian degeneration of the optic nerve. J Neurocytol 23:729-744.

Le Gal La Salle G, Robert JJ, Berrard S, Ridoux V, Stratford-Perricaudet LD, Perricaudet M, Mallet J (1993) An adenovirus vector for gene transfer into neurons and glia in the brain. Science 259:988-990.

Ludowyk PA, Willenborg DO, Parish CR (1992) Selective localisation of neurn-specific $T$ lymphocytes in the central nervous system. J Neurnimmunol 37:237-250.

Lund RD (1965) Uncrossed visual pathways of hooded and albino rats Scicnce 149:1506-1507.

Maehlen J, Olsson T, Zachau A, Klareskog L, Kristensson K (1989) Local enhancement of major histocompatibility complex (MHC) class 1 and II expression and cell infiltration in experimental allergic encephalomyelitis around axotomized motor neurons. J Neuroimmunol 23:125-132

Mason DW, Charlton HM, Jones AJ, Lavy CBD, Puklavec M, Simmonds SJ (1986) The fate of allogeneic and xenogeneic neuronal tissue transplanted into the third ventricle of rodents. Neuroscience 19:685-694.

Matyszak MK, Perry VH (1995) Demyelination in the central nervous system following a delayed-type hypersensitivity response to bacillus Calmette-Guérin. Neuroscience 64:967-977.

McGeorge AJ, Faull RLM (1989) The organization of the projection from the cerebral cortex to the striatum in the rat. Neuroscience 29:503-537.

Merrill JE, Ignarro LJ, Sherman MP, Melinek J, Lane TE (1993) Microglial cell cytotoxicity of oligodendrocytes is mediated through nitric oxide. J Immunol 151:2132-2141.

Molleston MC, Thomas ML, Hickey WF (1993) Novel major histocompatibility complex expression by microglia and site-specific experimental allergic encephalomyelitis lesions in the rat central nervous system after optic nerve transection. Adv Neurol 59:337-348.

Neumann H, Cavalié A, Jenne DE, Wekerle H (1995) Induction of MHC class I genes in neurons. Science 269:549-552.

Olsson T, Diener P, Ljungdahl $\AA$, Van Der Meide PH, Kristensson K (1992) Facial nerve transection causes expansion of myelin autoreactive $T$ cells in regional lymph nodes and $T$ cell homing to the facial nucleus. Autoimmunity 13:117-126.

Overbeek PA, Lai S-P, Van Quill KR, Wastphal H (1986) Tissue-specific expression in transgenic mice of a fused gene containing RSV terminal scquences. Science 231:1574-1577.

Pasquier DA, Kemper TL, Forbes WB, Morgane PJ (1977) Dorsal raphe, substantia nigra and locus coeruleus: interconnections with each other and the neostriatum. Brain Res Bull 2:323-339.

Paterson DJ, Jefferies WA, Green JR, Brandon MR, Corthesy P, Puklavec M, Williams AF (1987) Antigens of activated rat T lymphocytes including a molecule of $50,000 \mathrm{M}_{\mathrm{r}}$ detected only on CD4 positive T blasts. Mol Immunol 24:1281-1290. 
Pereira RA, Tscharke DC, Simmons A (1994) Upregulation of class I major histocompatibility complex gene expression in primary sensory neurons, satellite cells, and Schwann cells of mice in response to acute but not latent herpes simplex virus infection in vivo. J Exp Med 180:841-850.

Rao K, Lund RD (1989) Degeneration of optic axons induces the expression of major histocompatibility antigens. Brain Res 488:332-335.

Ridoux V, Robert JJ, Zhang X, Perricaudet M, Mallet J, Le Gal La Salle $G$ (1994) Adenoviral vectors as functional retrograde neuronal tracers. Brain Res 648:171-175.

Rinaman L, Milligan CE, Levitt P (1991) Persistence of fluoro-gold following degeneration of labeled motoneurons is due to phagocytosis by microglia and macrophages. Neuroscience 44:765-776.

Rixon FJ, McLauchlan J (1990) Insertion of DNA sequences at a unique restriction enzyme site engineered for vector purposes into the genome of herpes simplex virus type 1. J Gen Virol 71:2931-2939.

Robinson AP, White TM, Mason DW (1986) Macrophage heterogeneity in the rat as delineated by two monoclonal antibodies MRC OX-41 and MRC OX-42, the latter recognizing complement receptor type 3 . Immunology 57:239-247.

Selmaj K, Raine CS, Farooq M, Norton WT, Brosnan CF (1991) Cytokine cytotoxicity against oligodendrocytes. Apoptosis induced by lymphotoxin. J Immunol 147:1522-1529.

Sloan DJ, Wood MJ, Charlton HM (1991) The immune response to intracerebral neural grafts. Trends Neurosci 14:341-346.

Stewart AR, Tollefson AE, Krajcsi P, Yei S-P, Wold WSM (1995) The adenovirus E3 $10.4 \mathrm{~K}$ and $14.5 \mathrm{~K}$ proteins, which function to prevent cytolysis by tumor necrosis factor and to down-regulate the epidermal growth factor receptor, are locialized in the plasma membrane. J Virol 69:172-181.
Takada M, Hattori T (1987) The rat striatum: a target nucleus for ascending axon collaterals of the entopedunculo-habenular pathway. Brain Res 418:129-137.

Töpper R, Gehrmann J, Schwarz M, Block F, Noth J, Kreutzberg GW (1993) Remote microglial activation in the quinolinic acid model of Huntington's disease. Exp Neurol 123:271-283.

Veening JG, Cornelissen FM, Lieven PAJM (1980) The topical organization of the afferents to the caudatoputamen of the rat. A horseradish peroxidase study. Neuroscience 5:1253-1268.

Watanabe R, Wege $\mathrm{H}$, ter Meulen V (1983) Adoptive transfer of EAElike lesions from rats with coronavirus-induced demyelinating encephalomyelitis. Nature 305:150-153.

Wekerle H, Linington C, Lassmann H, Meyermann R (1986) Cellular immune reactivity within the CNS. Trends Neurosci 9:271-277.

Wood MJA, Byrnes AP, Kaplitt MG, Pfaff DW, Rabkin SD, Charlton IIM (1994a) Specific patterns of defective HSV-1 gene transfer in the adult central nervous system: implications for gene targeting. Exp Neurol 130:127-140.

Wood MJA, Byrnes AP, Pfaff DW, Rabkin SD, Charlton HM (1994b) Inflammatory effects of gene transfer into the CNS with defective HSV-1 vectors. Gene Therapy 1:283-291.

Yang Y, Nunes FA, Berencsi K, Furth EE, Gönczöl E, Wilson JM (1994) Cellular immunity to viral antigens limits E1-deleted adenoviruses for gene therapy. Proc Natl Acad Sci USA 91:4407-4411.

Yang Y, Li Q, Ertl HCJ, Wilson JM (1995) Cellular and humoral immune responses to viral antigens create barriers to lung-directed gene therapy with recombinant adenoviruses. J Virol 69:2004-2015.

Zhang ET, Richards HK, Kida S, Weller RO (1992) Directional and compartmentalised drainage of interstitial fluid and cerebrospinal fluid from the rat brain. Acta Neuropathol 83:233-239. 